\title{
Risk-opportunity analyses and production peak forecasting on world conventional oil and gas perspectives
}

\author{
Zhang Jian ${ }^{1,2,3 *}$, Sun Zandong, ${ }^{1,2}$ Zhang Yiwei ${ }^{1,2}$, Sun Youshun ${ }^{3}$ and \\ Nafi Toksoz ${ }^{3}$ \\ ${ }^{1}$ Lab for Integration of Geology and Geophysics, China University of Petroleum, Beijing 102249, China \\ ${ }^{2}$ State Key Laboratory of Petroleum Resources and Prospecting, China University of Petroleum, Beijing 102249, China \\ ${ }^{3}$ Earth Resources Laboratory, Massachusetts Institute of Technology, 77 Mass. Ave, Cambridge, MA 02139, USA
}

(C) China University of Petroleum (Beijing) and Springer-Verlag Berlin Heidelberg 2010

\begin{abstract}
To investigate the situation of conventional oil and gas, this paper examines the global oil and gas discoveries, proved reserves, production, consumption and price. All the influencing factors can be subjected to risk and opportunity analyses, so in the paper, we build upon a risk-opportunity analysis framework, which is a new train of thought. To forecast the peak time of oil and gas production, we used the methods of multi-Hubbert model forecasting and data forecasting. Our results showed that the world oil production will reach a peak between 2010 and 2015 and the gas production will reach a peak around 2030 Oil peak is coming and gas peak is on the way. The main purpose of forecasting oil and gas production peak is give people enough time for preparing mitigation and adaptation plans. This means taking decisive action well before the problem is obvious.
\end{abstract}

Key word: Production, reserve, risk, opportunity, forecasting

\section{Introduction}

There is an increasing concern that global oil production is close to peak and the peak will be followed by a rapid decline in production. On one hand, the oil industry, supported by organizations' reports (CGES, 2006; EIA, 2006; IEA, 2006; EIA, 2007; IEA, 2007), claim that there are sufficient oil resources to meet global demand for decades and adequate financial resources in a timely manner are put in place to explore, develop and produce the oil and gas. On the other hand, some organizations and individual debaters (Simmons 2005; ASPO, 2007; ODAC, 2009) claim that oil production may already have peaked or will soon peak due to the limited resources.

Most of the current peak oil forecasting models are derived from the Hubbert model (Hubbert, 1967). In 1956, Hubbert accurately predicted that the peak oil production point of the United States would arrive in 1971, and he developed a model for predicting the cumulate production and ultimate recoverable resources (URR), which was widely used and named as the Hubbert model (Hubbert, 1967). The model is conceptually simple, but based on several assumptions (Maugeri, 2004). Based on the production data

*Corresponding author. email: monsterzhang@gmail.com Received June 26, 2009 of many integrated oil fields, the oil production follows the "Central Limit Theorem" from statistics. Since then, some researchers have made detailed analysis of the Hubbert curve, and used it to forecast the increase of the world oil and gas reserves and production (Doucet, 1992; Campbell and Laherrere, 1998; Deffeyes, 2001; Bartlett, 2004).

Excluding the impact of political or other influences, geologist Jean Laherrère thought that the production growth curve should be a replica of the graph of discovery over time, and there is a direct relationship between the discovery peak and the production peak (Laherrère 1999; 2000). The Hubbert model's success in predicting U.S. peak production merely reflected the peculiar nature of this area, which was the most intensively explored and exploited area in the world at that time, so the pattern of production was not rendered by a one cycle curve but was marked by large discontinuities. Actually, the oil and gas production were impacted by many factors, such as exploration, development technology, economic factors, policies and regulations, so it showed multiple peaks which can be fitted with a multi-cycle model. Al-Jarri and Startzman extended the one-cycle Hubbert model to a multi-cycle one in 1999, and used the multi-cycle model to forecast the supply of the world natural gas in 2000 (Al-Fattal and Startzman, 1999; 2000). An analysis by Hirsch (2005) showed that while the shape of the oil production curve can be affected by mitigation efforts, mitigation efforts are also affected by the shape of the Hubbert curve. 
However, the normal and lognormal distributions of historical data are only adequate in relatively static environments when estimating the probable occurrence of future extreme events. It is very difficult to accurately estimate the likelihood of extreme events occurring. It is significant to provide a scientific foundation for working out the national oil and gas development strategy of China, compiling the long-term development plan of oil industry, guiding the policy of energy industry and enhancing the ability to protect the economic and social sustainable development.

All the factors influencing oil and gas can be subjected to risk and opportunity analyses. Therefore, in this paper, combining the model and data forecasting in static environments and risk and opportunity analyses in dynamic environments, there are two main points: First, such factors lead company decision makers to believe they can quantify their risks with unrealistic levels of precision, which often leads to overconfidence in their ability to manage risk, and to risks being underestimated. Second, we encourage decision makers to focus much of their attention exclusively on the downside risks at the expense of considering and trying to identify and exploit the opportunities that are associated with many uncertain situations.

\section{Factors analyses and evaluation}

\subsection{Discoveries of exploration}

There is some important information available from comparing the 100-year discovery curves with the volume of demand curves (Fig. 1). Oil and gas exploration achievements include the peak period of decline, with a strong sudden and unpredictable nature.

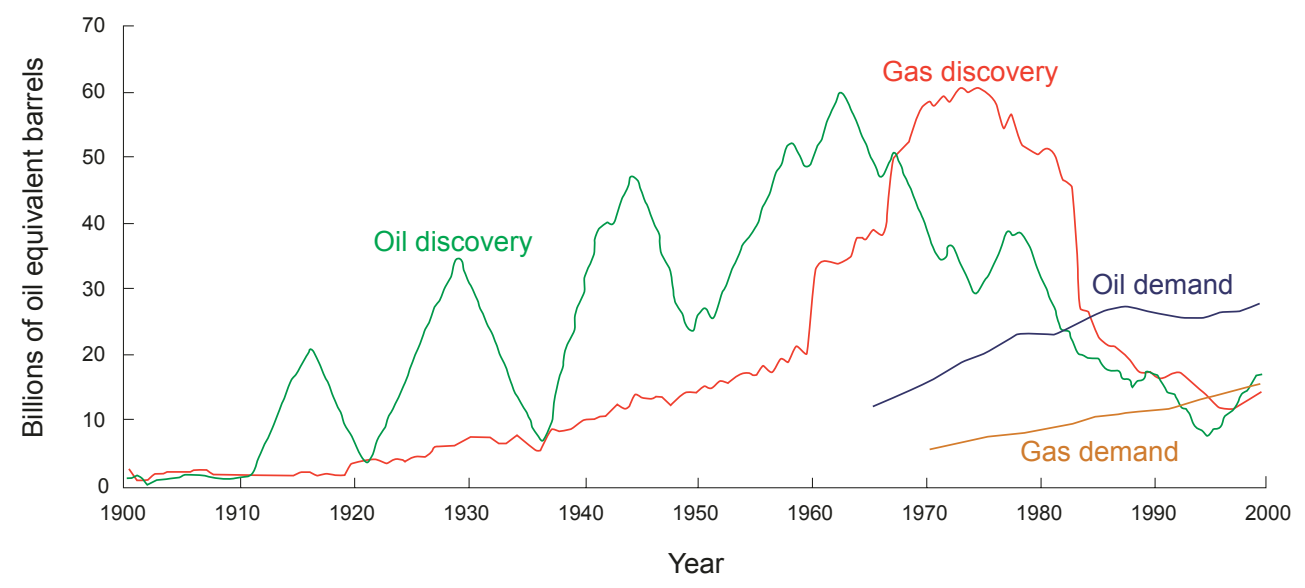

Fig. 1 100-year oil and gas discovery history and recent demand (Longwell, 2002)

The greatest period of oil exploration success was driven by large discoveries in Middle East, China, Russia, the North Sea and North Slope of Alaska. The peak of global oil exploration discoveries was in the decade 1960-1970, and the average volume of discoveries was 50 billion barrels per year $(\mathrm{BB} / \mathrm{yr})$. Nonetheless, as Fig. 1 indicates, discoveries have lagged behind demand since the early 1980s, when the global average discoveries were between 18 and $21 \mathrm{BB} / \mathrm{yr}$. In 1990s, the average discoveries decreased to $10 \mathrm{BB} / \mathrm{yr}$ (Fig. 1), and the oil discovery is less than half volume of consumption.

There is a similar story in natural gas. Gas demand, which is increasing slightly faster than the demand for oil, is being driven by rapid growth in its role as a clean fuel (Fig. 1). As happened with oil, gas resource discoveries exceeded demand for most of last century. Much of our global gas was discovered between roughly 1960 and about 1980 . The exploration success of gas was driven by major discoveries in Russia, Middle East, Netherlands and Indonesia (Longwell, 2002).

At the beginning of this century, some critics could note that new oil discoveries only account for one-fourth of what the world consumes every year (following a declining trend that began in the mid-1960s), and that the increase in claimed oil reserves is largely derived from upward revisions of existing fields.

In accordance with the standards of 500 million barrels as the giant oilfield, there were 76 discoveries in 1990s. As Klett and Schmoker (2003) have recently demonstrated, from 1981 to 1996 the estimated volume of oil in 186 well-known giant fields in the world increased from 617 to $777 \mathrm{bbl}$ without new discoveries. Since 2000, only two major oilfields were found in 2002, and there was no any discoveries in 2003 (Table 1).

Table 1 New discoveries of global exploration in 1990s (Lin, 2007)

\begin{tabular}{cccc}
\hline Year & $\begin{array}{c}\text { New discoveries } \\
/ 1 \mathrm{BB}\end{array}$ & Year & $\begin{array}{c}\text { New discoveries } \\
/ 1 \mathrm{BB}\end{array}$ \\
\hline 1992 & 7.80 & 1998 & 7.60 \\
1993 & 4.00 & 1999 & 13.00 \\
1994 & 6.95 & 2000 & 12.60 \\
1995 & 5.62 & 2001 & 8.90 \\
1996 & 5.42 & 2002 & 9.00 \\
1997 & 5.42 & 2003 & 2.27 \\
\hline
\end{tabular}




\subsection{Oil and gas reserves data}

The world's oil and gas data are unreliable. This has plagued the oil and gas market for many years. With peak oil production problems and continued high oil prices, this issue has become more and more serious. Today, when the oil industry is unable to increase production as quickly as it could last century, the market would like to have more precise data to judge the oil supply trends. The current opaque oil data could well be leading to serious misjudgment of global oil supply capacity.

Since 1980, OPEC announced their oil and gas reserves and production data was closed. Because oil and gas exploration was a national act, few companies venture far into international exploration and development activities. $80 \%$ world oil reserves belong to the national oil companies (NOCs) of oil-producing countries, and NOCs produce two thirds of the world's oil each year, so the international community has no unified management of oil data. The situation is that the world's most important oil data are not audited by independent third-party organizations.

Comparing the estimates of world proved oil and gas reserves from different organizations (Fig. 2), it was found that various world energy and financial institutions have significantly different statistics on the global oil and gas reserves. Different countries followed different theories and concepts, and then got dissimilar remaining proved reserves of the world. However, the data from Oil \& Gas Journal, Central Intelligence Agency (CIA) and Energy Information Administration (EIA) include about 173 billion barrels proved sand oil reserves in Canada, and World Oil and Bundesanstalt für Geowissenschaften und Rohstoffe (BGR) have included just the conventional oil, and the world proved conventional oil is about 1,200 billion barrels.

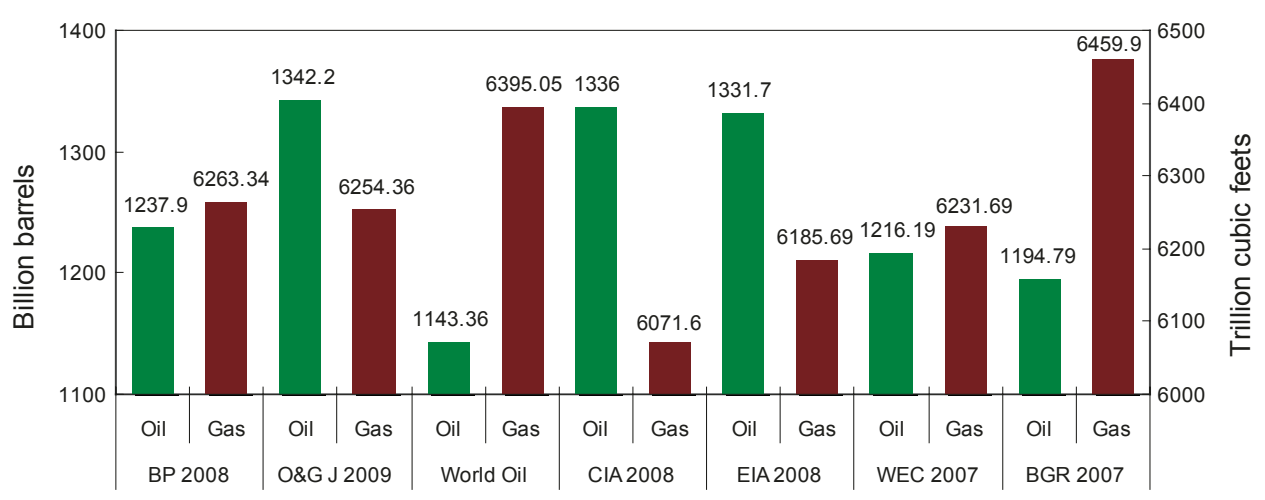

Fig. 2 Varying estimates of proved world oil and gas reserves from different organizations (Data source: BGR, 2007; WEC, 2007; BP 2008; CIA, 2008; EIA, 2008; O\&G, 2008)

\subsection{Production and consumption}

Now, the major oil-producing countries are located in the Middle East, South \& North America, Former Soviet Union (FSU) and Africa, and concentrated in some countries. The top 3 countries, Saudi Arabia, Russia and U.S., produce half the world's oil; U.S., Europe Union (EU) and China together consume half the global production. The top 20 countries produce $87 \%$ oil of the world and consumption $97 \%$ (Fig. 3 ).

The distribution of gas consumption and production resembles oil. The major gas producing countries are in the FSU, North America, Central Asia and Middle East. The top 3 producers, Russia, U.S. and EU produce $47 \%$ and consume $57 \%$ of the world's gas. The top 20 countries account for almost $90 \%$ of the world production and consumption (Fig. 3).

Global oil production is still increasing, but from 1965 to 2007, the rate of increase of oil production has declined rapidly (Fig. 4). Analysis from ASPO shows that the global oil production has not yet reached the oil production peak, because decline in giant fields is so far being offset by increases from other producers. Some think that the reduction of exploration discovery is connected with investment, but considering the high levels of investment, intensive exploration the levels of new discoveries have been disproportionately low. Recent oil price increases have led to oil exploration in areas where extraction is much more expensive, such as in extremely deep wells, extremely low temperatures, and environmentally sensitive areas or where high technology will be required to extract the oil. During recent years, although new reserves have been found in the deepwater of the Gulf of Mexico, South America and West Africa, because of the factors of the production cycle and development speed, these reserves have not led to an increase in global production.

On the other hand, the most oil-rich countries have minimized their investments during the last 20 years, mainly for fear of creating a permanent excess capacity such as that provoked the crisis in 1986 (when the oil prices plummeted to below \$10/bbl). Countries such as Saudi Arabia or Iraq (which together hold about $35 \%$ of the world's proven reserves of oil) produce petroleum only from a few old fields, although they have discovered but not developed more than 50 new fields each. So the constraint of oil-producing countries is another problem of the oil production.

However, the global gas production maintained a stable rate of increase from 1970 to 2007 (Fig. 4). This phenomenon indicates that the gas peak is not yet close and there are abundant gas reserves.

In the Middle East, Africa and Asia-Pacific, oil consumption grew by $3.0 \%$ per year between 2000 and 2007 (Kjärstad and Johnsson, 2009). In total, these three regions accounted for more than $70 \%$ of the total worldwide increase in oil consumption between 2000 and 2007. Economic 

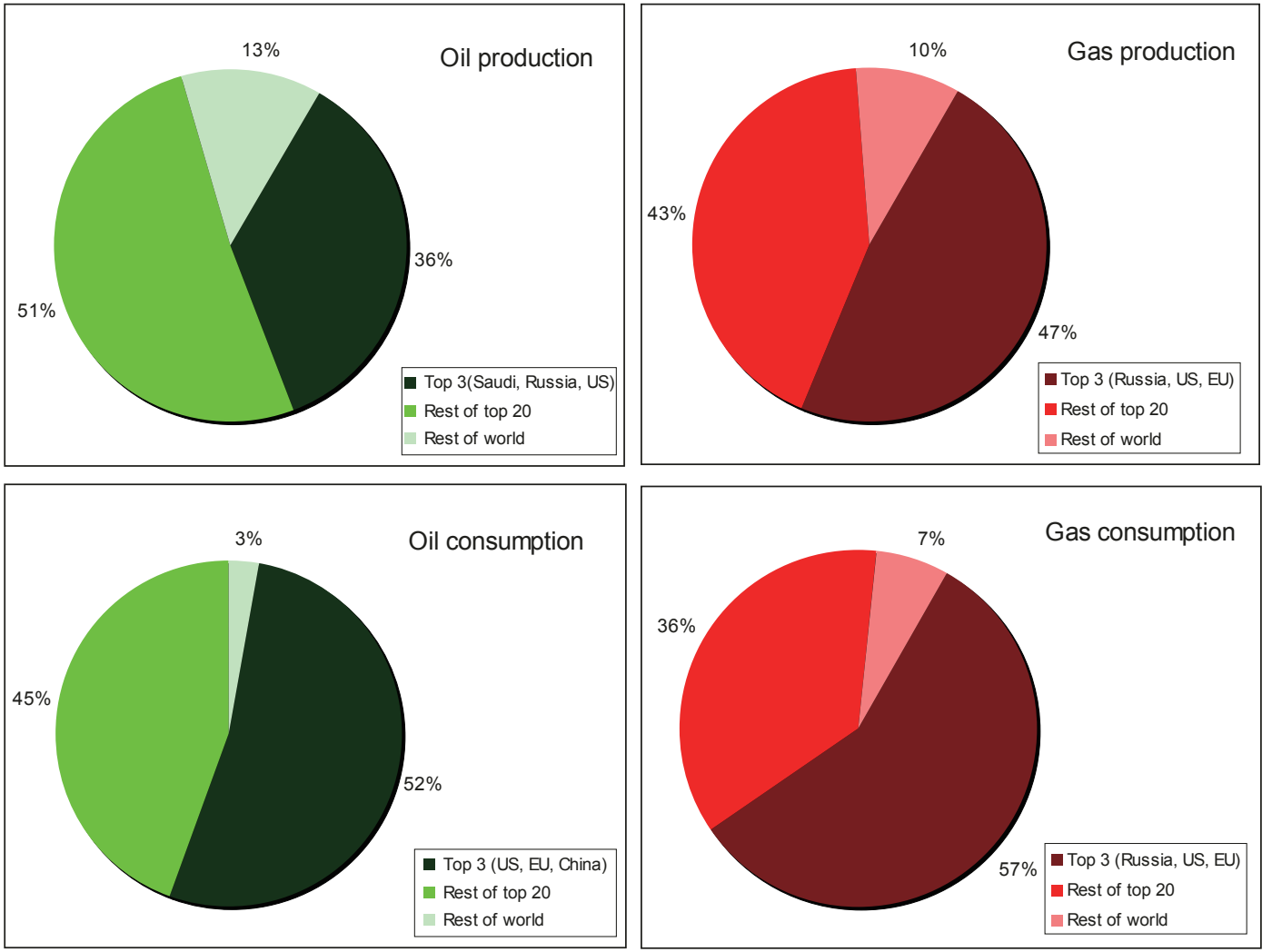

Fig. 3 Distribution of oil and gas production and consumption (Data source: CIA, 2008)

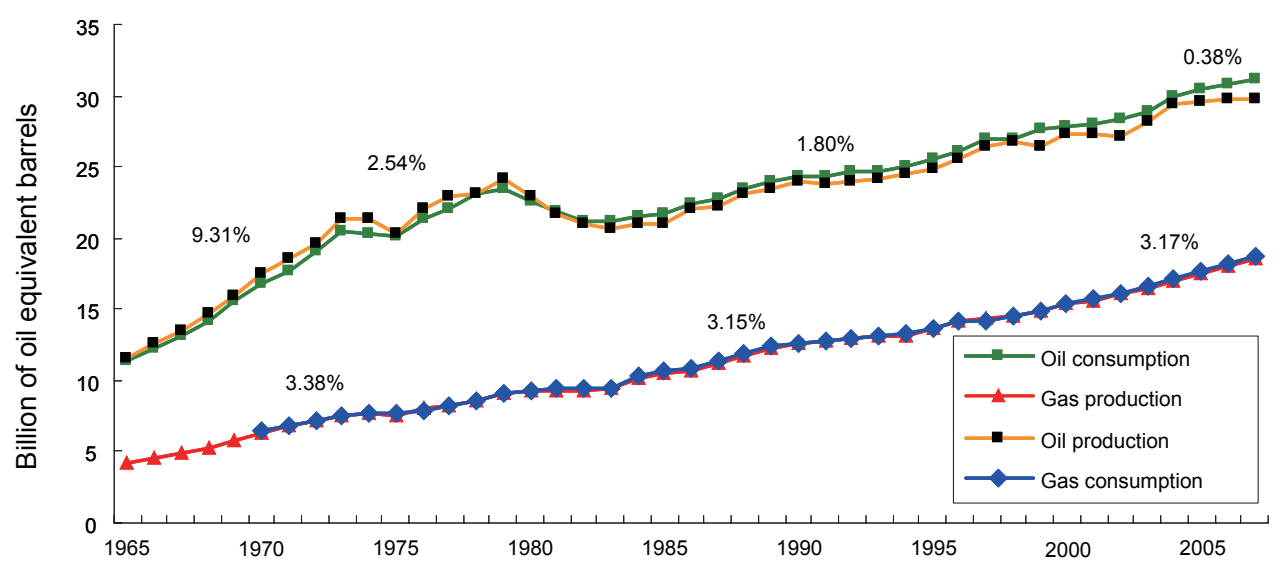

Fig. 4 World production and consumption data of oil and gas (Data Source: BP 2008; CIA 2008)

growth, increasing population, urbanization and infrastructure development will drive growth in demand for oil and gas in the so called BRIC countries (Brazil, Russia, India, and China). For example, car sales are booming in the BRIC countries which will lead to increasing oil consumption.

All the information indicates that consumption of oil and gas will increase rapidly. However, climate change has the potential to significantly alter future demand for oil, in particular considering the fact that the global $\mathrm{CO}_{2}$ emissions should be reduced by $50 \%-80 \%$ between 2000 and 2050 to prevent the global temperature from increasing $2.0-2.4{ }^{\circ} \mathrm{C}$ (IPCC, 2007).

A global concerted effort to mitigate climate change may, alone or together with concerns for energy security, have the potential in the long term to profoundly reduce demand for oil and gas. Concerns for energy security are already leading to steps being taken to curb growth in demand in USA, European Union and China, as shown by IEA (IEA, 2007). If the world seriously wants to reduce $\mathrm{CO}_{2}$ emissions in order to meet the Intergovernmental Panel on Climate Change (IPCC) emission reduction targets, drastic measures will have to be taken to reduce consumption of fossil fuels including oil and gas.

\subsection{Oil price}

Production and consumption determine the direction of oil price fluctuations, which also shows the supply and demand situation. Actually, oil price is governed by a combination 
of factors, and three of those factors are powerful enough to allow us to ignore the influence of the others. Firstly, demandled factors of big consumers (such as the United States, Japan and China): the degree of dependence on energy demand and consumption decisions; secondly, OPEC supplies: OPEC is one of the main sources of supply for world oil; however, limited capacity, geopolitical, and many other factors led to supply-side uncertainties; thirdly, oil futures trading has a significant influence on the price of oil in the world market.

Fig. 5 shows the changes of world crude oil prices from 1861 to 2008.7 . The oil price data is from three parts: 18611944 data depend on the US average; 1945-1983 data are Arabian Light which posted at Ras Tanura; and 1984-2008 data are from Brent crude oil futures. Two curves displayed the price of crude oil which is expressed in the value of the dollar at that time (dark green) and in 2006 dollars (light green). Considering the value of the dollar in 2006, there were two high-value areas: one was at the beginning of crude oil-low production levels due to high cost, and the other was during the 1980 Iranian revolution, which led to the oil crisis and higher oil prices. If the value of the dollar at that time, apart from that in the 1980 oil crisis in higher level, oil prices have been maintained at a very low level for more than 100 years. From 2004, oil price begin to rise at a very fast rate. From July 2006 to July 2008 , the oil price rose from US $\$ 60$ to more than US $\$ 140$ a barrel. It was characterized by variations and poses several questions: First, the low oil price era has ended, and long-term oil prices will be maintained at a relatively high level. Second, the world economy became more and more oil-dependent, and the oil supply and demand relationship directly affects the world economic development, especially the big countries' economies. Third, the U.S. economic recession and the depreciation of the dollar accelerate the price increase.

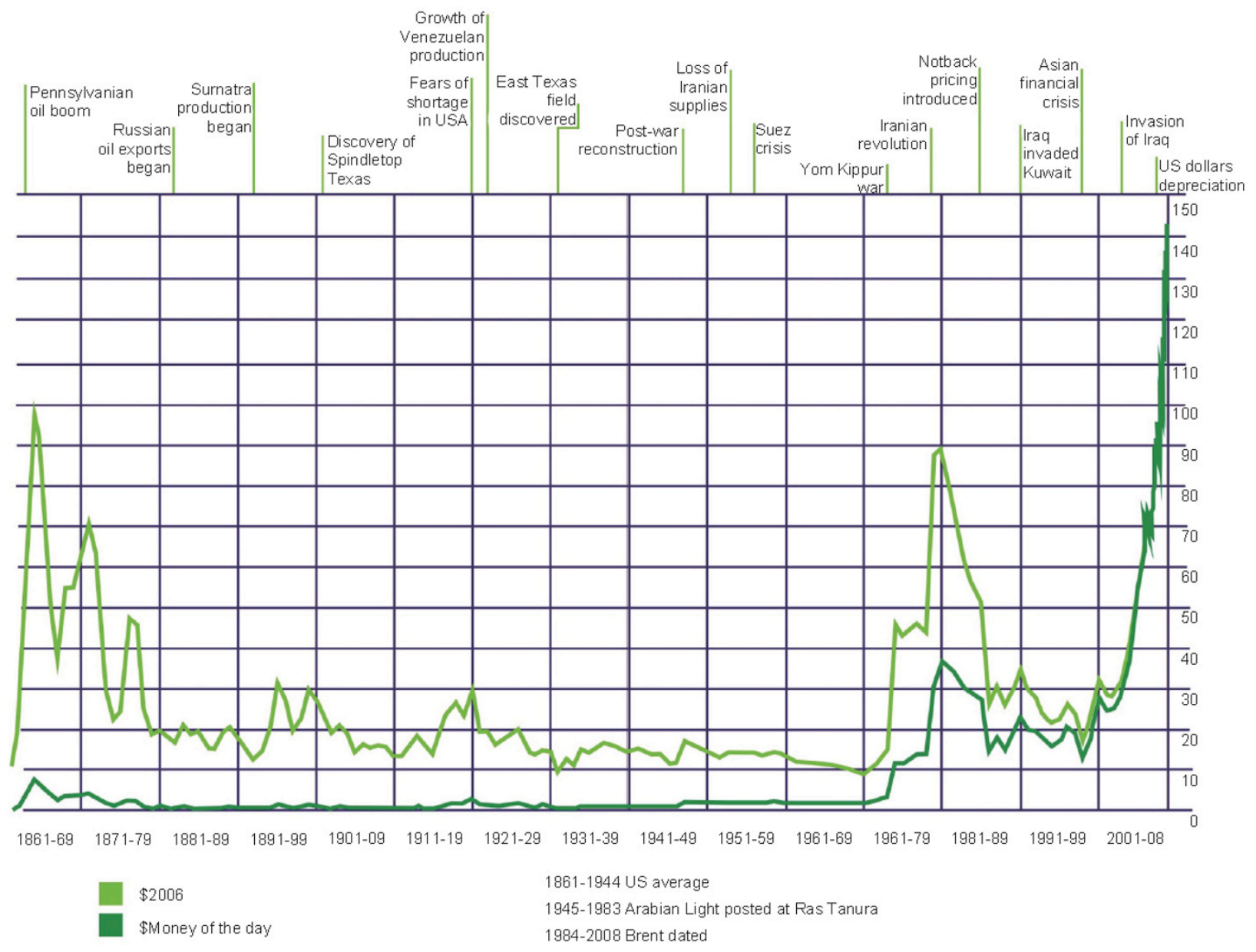

Fig. 5 Oil price from 1861 to 2008.7 (Data source: BP and Brent, modified)

\section{Risk-opportunity analyses}

Opportunity and risk, which go hand-in-hand, are two facets of uncertainty. There are good reasons why oil and gas companies more rigorously evaluate and, where possible, quantify the risks to which their operations, physical assets, and financial resources are exposed.

The following approach grounds the analysis in the context of proved reserves at the national and regional level, statistics that are readily available. The quality of the estimates of proved reserves at the national level varies between regions, and these figures are rightly questioned as unverifiable numbers presented by several resourcerich nations. However they are useful for distinguishing the resource endowments on the order of magnitude scale.

We provide a fast and effective way to systematically 
evaluate a large number of countries in a superficial but rigorous manner. Scores are assigned to five factors for broadly evaluating country risk and to another five factors for broadly evaluating country opportunity.

The five attributes proposed for scoping risk analysis are focused mainly on political, business, and fiscal risks: 1) political instability; 2) corruption; 3) administrative burden; 4) community-labor disputes; 5) regressive and inflexible fiscal crisis.

These five attributes proposed for scoping opportunity analysis are focused mainly on techniques, operations, and finance: 1) probability to find large reserves; 2) exploration and development costs; 3) operation ease degree; 4) access to equity-debt funding; 5) access to infrastructure-markets.

Applying a simple scoring system makes the evaluation process quicker and more transparent. Here a 1-5 scale is applied to both risk and opportunity, but extending in different directions from a zero point, which is an impossible score implying an attribute with no uncertainty risk or opportunity (Fig. 6).

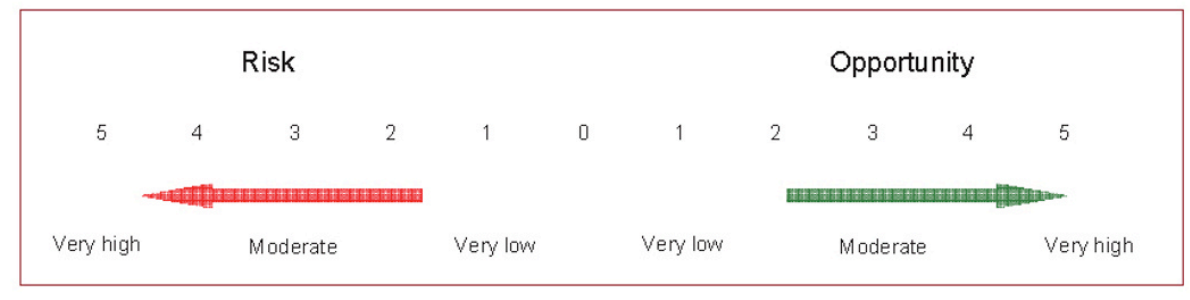

Fig. 6 Score system for risk-opportunity analyses

The proposed semiquantitative scheme has the advantage of distancing high opportunity from high risk in the bubble chart. It helps to have a clear description of each score to reduce ambiguity and to improve precision. Thus there is a more precise definition of each number.

If a score of 1-5 is assigned to each attribute and the scores of all the five attributes of opportunity and of risk are added separately to yield two scores, then the two scores can vary between 5 and 25 .

To ground this simplified analysis in a global context, the risk-opportunity indices for a spectrum of major resource holders can be evaluated and presented graphically with respect to their resource volumes. Fig. 7 and Fig. 8 show such analysis for top 20 proved reserves owner countries; Fig. 9 and Fig. 10 show the analysis for 7 world regions (2007 yearend volumes, BP Statistical Review and CIA Fact Book in 2008). It is appropriate to use the proved reserves statistics above as they are the volumes with which the industry definitely believe with the highest level of confidence.

Depended on this framework, the point of the simple scales proposed is that they can be adjusted and updated easily and regularly in response to events, different opinions, or changing environments, in a transparent and rigorous manner. It may be more relevant to certain companies, portfolio strategies, or situations. It is perhaps also important to recognize that the global framework used to ground the risk-opportunity analysis can in some cases themselves hide or obscure some opportunity.

For the integrated risk and opportunity analysis in the petroleum industry is of most valuable in seeking out opportunities, the analysis needs to be grounded in a global vision and the framework needs to provide space for opportunities to exist.

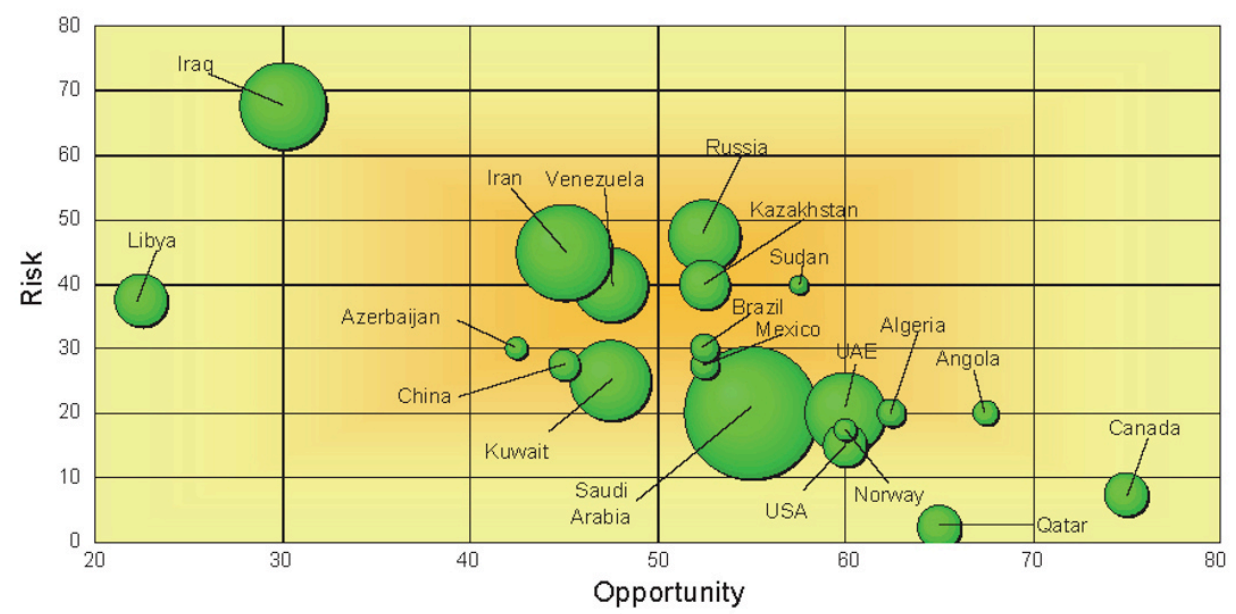

Fig. 7 Risk-opportunity analyses of top 20 oil owner countries (Data source: BP, 2008; CIA, 2008) 


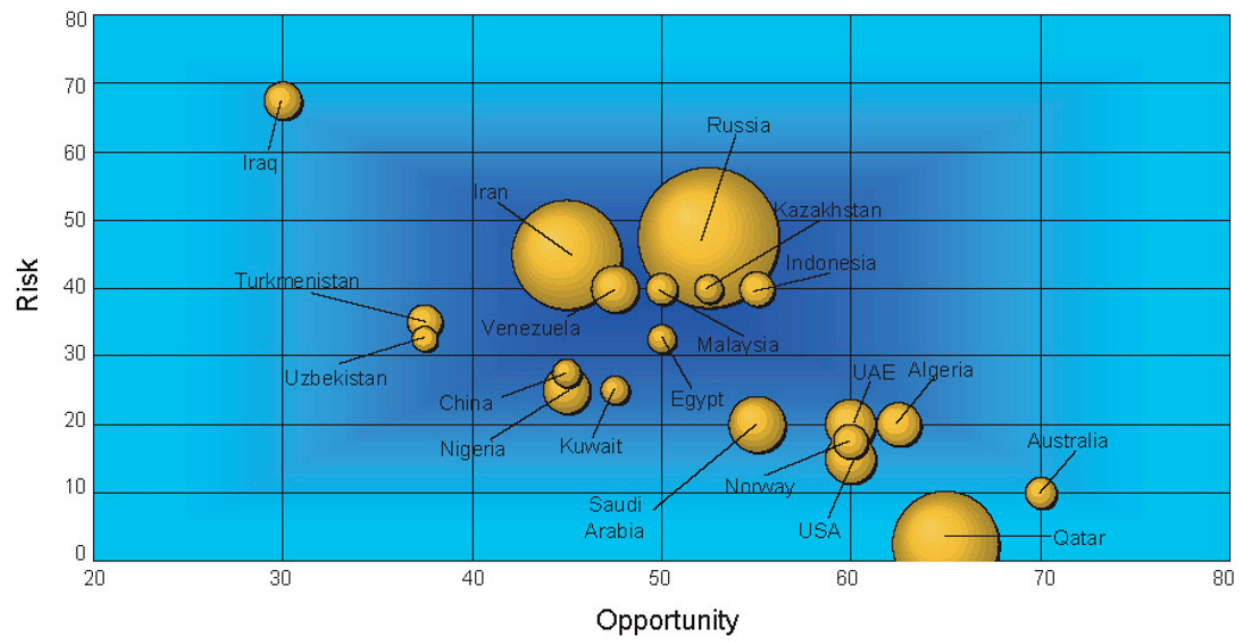

Fig. 8 Risk-opportunity analyses of top 20 gas owner countries (Data source: BP, 2008; CIA, 2008)

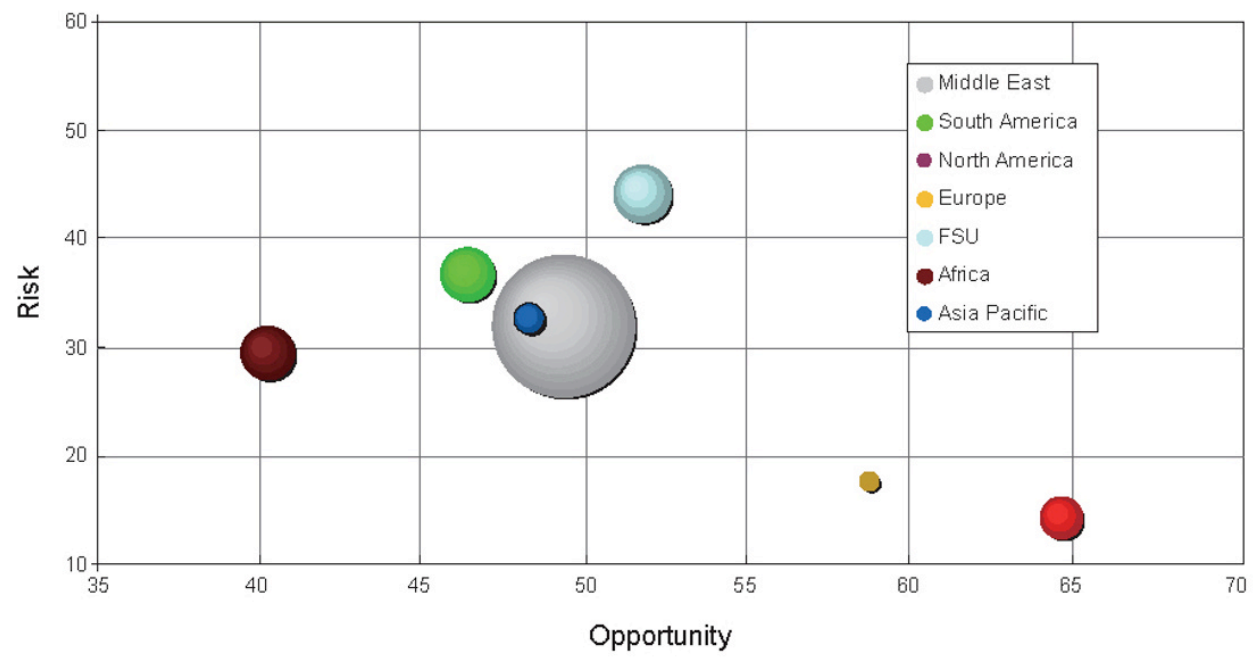

Fig. 9 Oil risk-opportunity analyses of 7 world regions (Data source: BP, 2008; CIA, 2008)

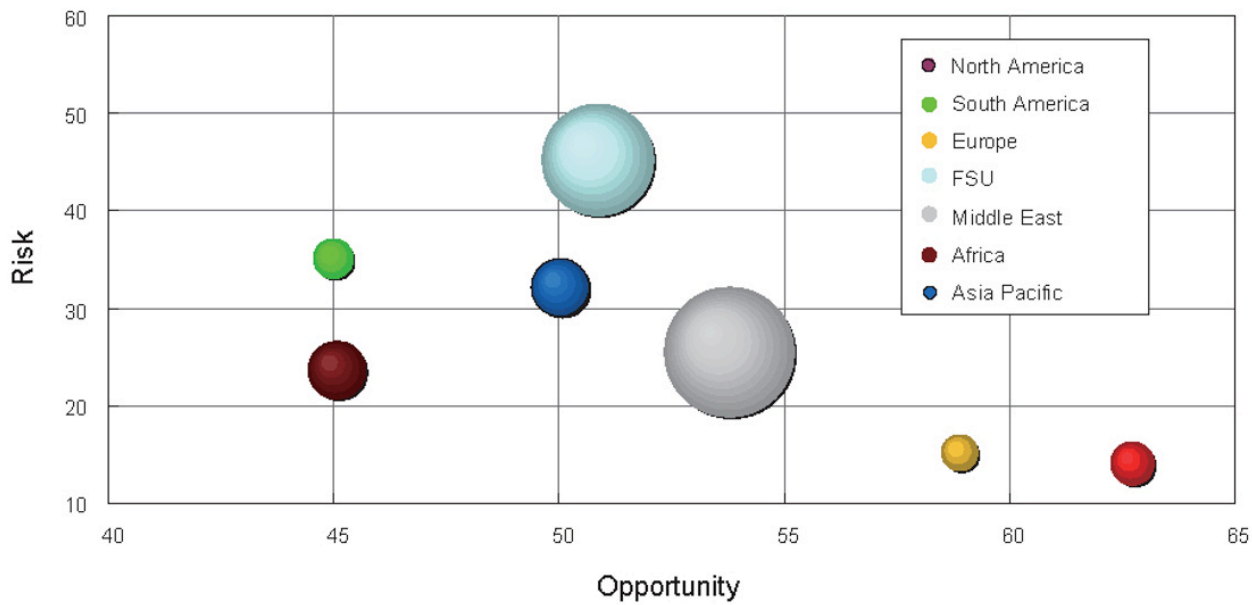

Fig. 10 Gas risk-opportunity analyses of 7 world regions (Data source: BP, 2008; CIA, 2008) 


\section{Peak oil and gas of the world}

\subsection{Source of data}

In this study, we use historical oil and gas reserves data acquired from OGJ (Oil and Gas Journal) database (O\&G, 2008), BP Statistical Review (BP, 2008), EIA (Energy Information Administration) (EIA, 2008)and WEC (World Energy Council) (WEC, 2007) and World Oil. Annual production data of oil and gas was obtained from BP Statistical Review for the period of 1965-2007. Annual oil and gas production data from EIA (1980-1997) were also used to validate the dubious data and replace it if necessary.

\subsection{Forecasting by Multi-Hubbert model}

According to the factors analysis above, these additional cycles apparently results from the change of the exploration technology, regulations, and economic and/or political events. The Hubbert model with a single production cycle does not allow for these factors. To account for the additional production cycles we used a modified version of the Hubbert model referred as the "multicyclic Hubbert" model (Al-Fattal and Startzman, 1999). The logistic curve or the cumulative production of the multicyclic model can then be expressed as

$$
Q=\sum_{i=1}^{k} \frac{2\left(Q_{m}\right)_{i}}{\left\{1+\cosh \left[b\left(t-t_{m}\right)\right]\right\}_{i}}
$$

First, we examined the historical production data and determined the number of production cycles. At a later stage of the modeling process, the additional cycles have a good fit for the actual situations. The historical cycles are needed to fit, and the future cycles are needed to forecast. Second, we set a problem to solve the model, Eq. 1 using a nonlinear least-square solver with initial guesses for the parameters $b, Q_{\mathrm{m}}$ (annual maximum production) and $t_{\mathrm{m}}$ (the year at peak production) based on the number of production cycles. The parameters $i$ and $k$ indicate the number of cycles. For example, production data exhibiting three production cycles require nine parameters to solve the model.

Fig. 11 shows the world aggregated oil model which fits the data very well. Because the Middle East had in 2006 the most abundant oil resources with $31 \%$ of the world's production and $61 \%$ of the reserves, the oil growth rate and the change characteristics of the production curve of the world are very similar to that of the Middle East. By the year 2030, 1611.6 BB of oil will be produced approximately from 1965 to 2030, including 659.2 BB from 2008-2030. Our predicted results show that the world conventional oil production will peak at an approximate rate of $29.14 \mathrm{BB} /$ yr $\left(39.76 \times 10^{8} \mathrm{t}\right)$ by the year 2015 . The world oil production chart shows a flat production region, called the middle region, extending from the year 2013 until the year 2017 with about the same rate as the peak. After the year 2018, the production rate starts declining steadily and the curve gets flatter. The Canada oil production data includes both tar sands oil and conventional oil. The total oil production is $1.2 \mathrm{BB} / \mathrm{yr}$ (BP 2008). In 2007, the production of sand oil is $0.51 \mathrm{BB} / \mathrm{yr}$ and the increase rate is approximately $4 \%$ (CNEB, 2008). If we just consider the conventional oil production in Canada, the world oil production will peak by the year 2012 or 2013 .

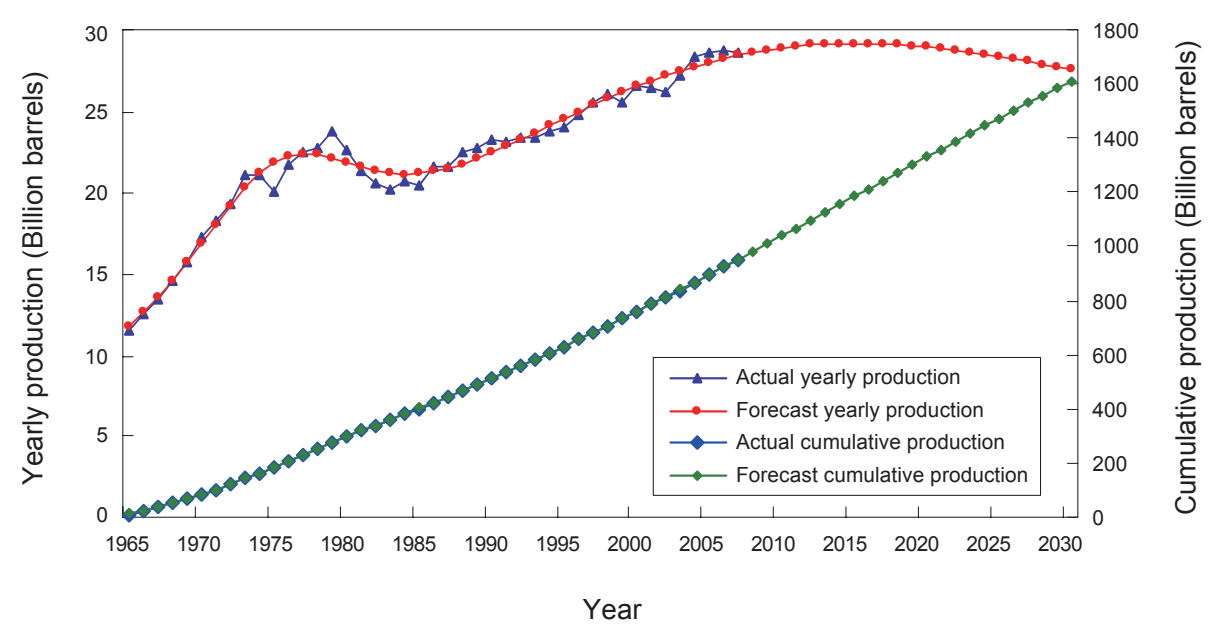

Fig. 11 Forecasting of world oil production by multi-cycle Hubbert model

Fig. 12 shows the world aggregated gas model which fits the data better than oil model. By the year 2030, around 5431.7 TCF (trillion cubic feet) of gas will have been produced from 1965 to 2030 , including 2764.5 TCF from 2008 to 2030. Our results show that the world conventional gas production will peak at an approximate rate of $130 \mathrm{TCF}$ by the year 2030-2035. The world gas production shows an increased production trend. Extending from the year 1965 until the year 2010, the production rate increased rapidly. From the year 2011 to the year 2028, the production rate starts increasing less rapidly and the curve gets flatter. After the year of 2028, the world conventional gas production will peak and have a flat production region. 


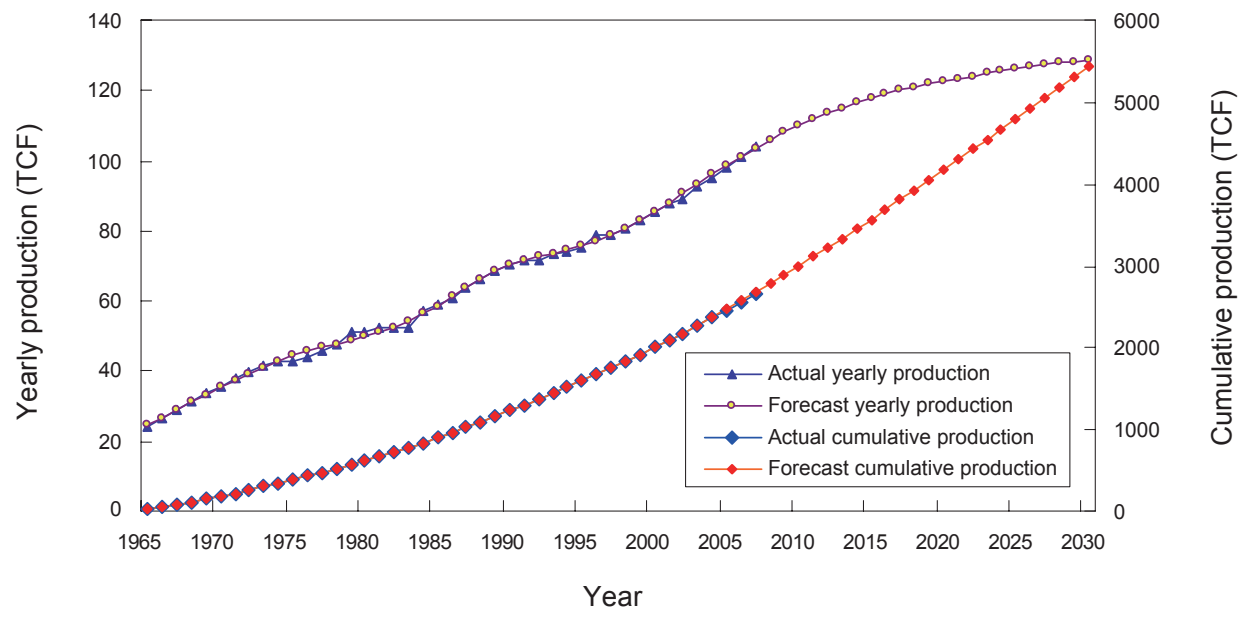

Fig. 12 Forecasting of world gas production by multi-cycle Hubbert model

\subsection{Data forecasting}

The production rate of anything on the finite Earth may follow one of three major patterns as a function of time : normal (Gaussian), S-shaped, or exponential (Patzek, 2008). In the early stages of production, these three patterns are practically indistinguishable, leading some to believe that the production rates of exhaustible resources (coal, oil, natural gas, iron ore, copper ore, etc.) can grow exponentially. In reality, the high quality resources (oil and gas) from the environment are limited, and these rates first grow and then decline. At best, these yields follow the S-shaped curves, which have been proved in section 3.2. Therefore, the cumulative amounts of oil and gas production are doomed to meet the cumulated oil and gas consumption of civilization and economics. The point will be the peak of the energy.

We consider the cumulated global production of conventional oil and gas between 1860 and 2007. The historical data are divided into two parts: 1860-1997 and 1997-2007. The total consumption of conventional oil and gas between 1860 and 1997 are 782 BB and 2228 TCF (Rogner, 1997; Nakicenovic and Riahi, 2001; Kuuskraa and Cutler, 2004). The total consumption between 1998 and 2007 are 262 $\mathrm{BB}$ and 832 TCF from BP Statistical Review (BP, 2008).
Comparing the world proved oil reserves from different organizations (Fig. 2), the difference of data is caused mainly by the oil sands of Canada. The estimation for Canada's proved reserves made by BP includes 21.0 billion barrels of oil sands, and not included but reported separately is an additional 152.2 billion barrels of Canadian oil sands defined as remaining established reserves. The estimation of Canadian proved reserves by the Oil \& Gas Journal includes 5.392 billion barrels of conventional crude oil and condensate reserves and 173.2 billion barrels of oil sands reserves. The estimation for Canada oil reserves by World Oil includes 20.665 billion barrels of oil sands and bitumen. It excludes another 153 billion barrels of oil sands and bitumen claimed by Canadian authorities. Finally, the proved oil reserves are $1173 \mathrm{BB}$, the average value from different organizations.

By analyzing the oil annual consumption and oil reserves data between 2000 and 2007, the average rate of increase of consumption and proved reserves are $1.59 \%$ and $2.36 \%$, respectively. Fig. 13 shows the different scenarios peak time of conventional oil. Our result shows that the world conventional oil production will peak by the year 2009 with no growth rate of proved reserves, and the proved reserves will be declined, gradually and smoothly, less than consumption requirement at 2036 . If the growth rate of

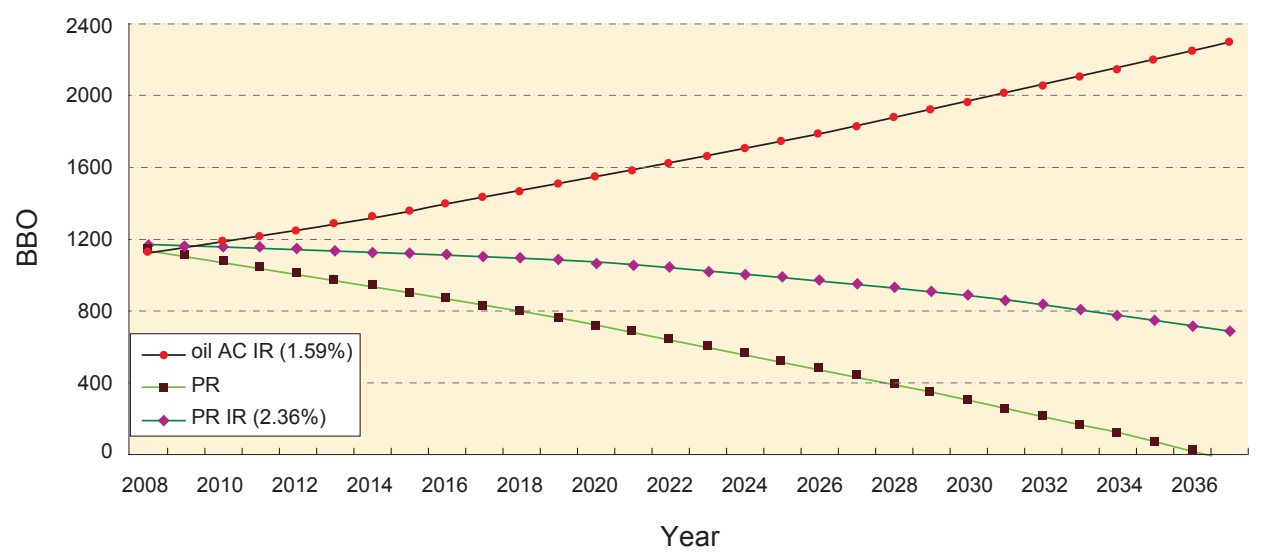

Fig. 13 Peak time of conventional oil Notes: $\mathrm{AC}=$ Accumulated consumption; $\mathrm{PR}=$ Proved reserves; $\mathrm{IR}=$ Increasing rate 
proved oil reserves is $2.36 \%$, the production will peak by the year 2011 and be declined less than consumption requirement at 2051

Comparing the world proved gas reserves from different organizations (Fig. 2), the average value of the proved data are 6288.6 TCF. By analyzing the annual gas consumption and gas reserves data between 2000 and 2007, the average increasing rates of consumption and proved reserves are $2.67 \%$ and $2.91 \%$, respectively. Fig. 14 shows the different scenarios peak time of conventional gas. Our result shows that the world conventional gas production will peak by the year 2020 with no growth rate of proved reserves, and the proved reserves will be declined, gradually and smoothly, less than consumption requirement at 2042. If the growth rate of proved gas reserves is $2.67 \%$, the production will peak by the year 2037 and be declined less than consumption requirement at 2069.

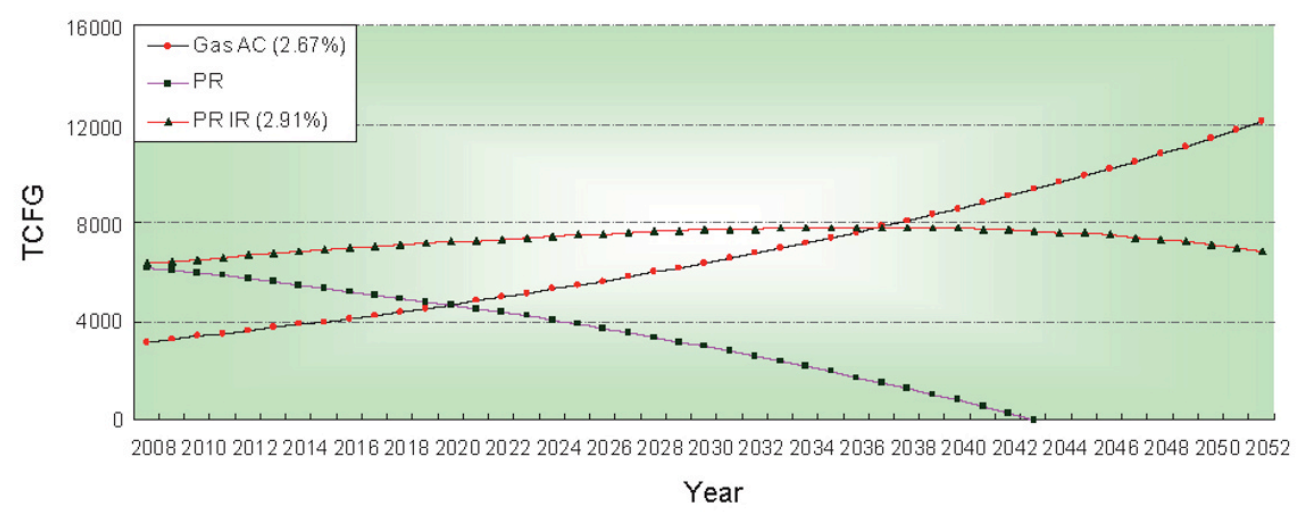

Fig. 14 Peak time of conventional gas

\section{Conclusions}

1) We built upon the risk-opportunity analysis framework for strategic evaluation. All the influencing factors can be included in this analysis. Opportunities will remain obscured or buried deep below the risks, no matter how detailed and quantitative the analysis, if risk analysis is considered in isolation or risk-opportunity analysis is within a constrained framework. Decision makers can identify and exploit the opportunities that are associated with many uncertain situations.

2) Our multi-cycle Hubbert model results show that the world will reach peak oil production at about 2015 and peak gas production around 2030. The global oil peak is coming and the outlook for gas production is still optimistic for the next decade. The oil peak precedes gas peak, but the time interval between the two is not predetermined.

3) Although the results of multi-cycle Hubbert model and data model forecasting are not going all the way, the results from data model are reliable. The reserves will be increased slightly and converted to production depending on technological innovations. There are several potential reserves growth points, such as unconventional oil gradually changing into conventional sources, EOR (enhanced oil recovery) technology, deepwater exploration and circumarctic resource prospecting, and so on. The parameters have already considered these points.

4) The Stone Age did not end for lack of stone, and the Oil Age will end long before the world runs out of oil. The main and obvious purpose of forecasting is to give people enough time to prepare mitigation and adaptation strategies, which will require an intense effort over decades. If mitigation and adaptation were to be too little, too late, world supply/demand balance will be achieved through massive demand destruction (shortages), which would translate to significant economic hardship. Effective mitigation and adaptation means taking decisive action well before the problem is obvious.

\section{References}

Al-Fattal S M and Startzman R A. Analysis of worldwide natural gas production. SPE 57463. 1999. 1-14

Al-Fattal S M and Startzman R A. Forecasting world natural gas supply. SPE 62580. 2000. 1-11

ASPO. Personal communication with Kjell Aleklett. The Association for the Study of Peak Oil and Gas. 2007

Bartlett A.A. An analysis of U.S. and world oil production patterns using Hubbert-style curves. Mathematical Geology. 2004. 32(1): 1-17

BGR. Reserves, Resources and Availability of Energy Resources. Annual Report. 2007

BP. BP Statistical Review of World Energy. 2008

Campbell C J and Laherrere J H. The end of cheap oil. Scientific American. 1998. 78-83

CGES. The Oil Market-Key Questions. Centre for Global Energy Studies. 2006

CIA. World Fact book. Central Intelligence Agency. 2008

CNEB. An Energy Market Assessment: Canadian Energy Overview 2007. Canada National Energy Board. 2008

Deffeyes K S. Hubbert's Peak: The Impending World Oil Shortage. Princeton, New Jersey, USA : Princeton University Press, 2001

Doucet P S P. Mathematical Modeling in the Life Sciences. Melksham: Redwood Press, 1992

EIA. International Energy Outlook 2006. US Energy Information Agency. 2006

EIA. International Energy Outlook 2007. US Energy Information Agency. 2007

EIA. Sources of Foreign Reserve Estimates. Energy Information Administration. 2008

Hirsch R L. The inevitable peaking of world oil production. Atlantic Council Bulletin. 2005. XVI(3): 1-10

Hubbert K M. Degree of advancement of petroleum exploration in the 
United States. AAPG Bulletin. 1967. 51(11): 2207-2227

IEA. World Energy Outlook 2006. International Energy Agency. 2006

IEA. World Energy Outlook 2007. International Energy Agency. 2007

IPCC. Fourth Assessment Report. Intergovernmental Panel on Climate Change. 2007

Kjärstad J and Johnsson F. Resources and future supply of oil. Energy Policy. 2009. 37: 441-464

Klett T R and Schmoker J W. Tectonic setting of the world's giant oil \& gas fields. AAPG Memoir. No. 78. 2003.107-100

Kuuskraa V A and Cutler J C. Natural Gas Resources, Unconventional Encyclopedia of Energy. New York, Elsevier. 2004. 257-272

Laherrère J H. Learn strengths, weaknesses to understand Hubbert curve. Oil \& Gas Journal. 2000. 98(16): 63-74

Laherrère J H. World oil supply-what goes up must come down: when will it peak? Oil \& Gas Journal. Feb. 1, 1999. 57-64

Lin Y. Latter Half Barrel Oil-Global Economy Strategic Recombination, ed. Dai Y and Liu Y. 2007. Beijing: Chemical Industry Press. 43-45

Longwell $\mathrm{H} \mathrm{J}$. The future of the oil and gas Industry: past approaches, new challenges. World Energy. 2002. 5(3): 100-104
Maugeri L. Oil: Never cry wolf-why the petroleum age is far from over. Science. 2004. 304: 1114-1115

Nakicenovic N and Riahi K. An assessment of technological change across selected energy scenarios. World Energy Council Research Report. 2001

O\&G. New estimates boost worldwide oil, gas reserves. Oil \& Gas Journal. Dec. 22, 2008. 20-23

ODAC. Preparing for Peak Oil: Local Authorities and the Energy Crisis. Oil Depletion Analysis Centre. 2009

Patzek T W. Exponential growth, energetic Hubbert cycles, and the advancement of technology. Archives of Mining Sciences of the Polish Academy of Sciences. 2008. 1-22

Rogner H H. An assessment of world hydrocarbon resources. Annual Review Energy Environment. 1997. 22: 217-262

Simmons M R. Twilight in the desert. The coming Saudi oil shock and the world economy. 2005

WEC. Survey of Energy Resources 2007. World Energy Council. 2007

(Edited by Zhu Xiuqin) 